\title{
Determination of Polycyclic Aromatic Hydrocarbons in Coffee and Coffee Substitutes using Dispersive SPE and Gas Chromatography-Mass Spectrometry
}

\author{
Anna Sadowska-Rociek • Magdalena Surma • \\ Ewa Cieślik
}

Received: 7 January 2014 / Accepted: 15 April 2014 /Published online: 30 April 2014

(C) The Author(s) 2014. This article is published with open access at Springerlink.com

\begin{abstract}
The purpose of this study was to evaluate the application of dispersive solid-phase extraction with the use of primary secondary amine (PSA), $\mathrm{NH} 2$ and strong anion exchange (SAX) sorbents for polycyclic aromatic hydrocarbon (PAH) determination in samples of coffee. The final extracts were analysed by gas chromatography selected ion monitoring mass spectroscopy (GC-SIM-MS). The results indicated that cleanup with PSA and SAX sorbents followed by final solvent exchange from acetonitrile to hexane (liquidliquid extraction, LLE) was the best variant of the method, resulting in the cleanest extracts and satisfactory compound recoveries (70-104 \%) for examined compounds in coffee samples. In the study of real samples, the concentrations of PAH markers (benzo $[a]$ anthracene, chrysene, benzo $[b]$ fluoranthene, benzo $[a]$ pyrene) were higher for natural roasted coffee $\left(7.20-68.15 \mathrm{~m} \mathrm{~kg}^{-1}\right)$, than for instant coffee (2.97$\left.19.55 \mu \mathrm{g} \mathrm{kg}^{-1}\right)$ and cereal coffee $\left(8.15-15.35 \mu \mathrm{g} \mathrm{kg}^{-1}\right)$, and the sum of PAHs was also higher in natural and instant coffees compared to coffee substitutes $\left(364,343\right.$ and $265 \mu \mathrm{g} \mathrm{kg}{ }^{-1}$, respectively). However, in all samples of coffee, light (threering) PAHs dominated within the identified compounds and phenanthrene was the most abundant compound, approaching $209.67 \mu \mathrm{g} \mathrm{kg}^{-1}$ in roasted coffee.
\end{abstract}

Keywords Coffee $\cdot$ Coffee substitute $\cdot$ PAHs $\cdot$ Dispersive SPE - GC-MS

A. Sadowska-Rociek $(\square) \cdot$ M. Surma $\cdot$ E. Cieślik

Malopolska Centre of Food Monitoring, Faculty of Food

Technology, University of Agriculture in Krakow, Balicka 122,

30-149 Krakow, Poland

e-mail: asadowska-rociek@ar.krakow.pl

\section{Introduction}

Coffee and coffee substitutes are one of the most popular beverages in the world, and its consumption is steadily increasing. Coffee beans contain hundreds of chemical substances including carbohydrates, fats, water, proteins, vitamins, organic acids, alkaloids such as caffeine, minerals and flavouring substances. Polyphenols (mainly chlorogenic acids) are other important component of coffee demonstrating anti-inflammatory, antibacterial, and anti-atherosclerotic activity (Cano-Marquina et al. 2013; Grover et al. 2013). Coffee substitutes, a natural alternative for coffee, are prepared from the roasted cereals and vegetables such as barley, corn, figs, dates, peanuts, soybeans, chicory or sugar beets (Belitz et al. 2009; Lee and Shin 2010). Roasting is a crucial step for the production of these beverages. The process is usually carried out in the temperature range of $120-230^{\circ} \mathrm{C}$. This allows for the development of aroma, colour and flavour, which are essential for the characterisation of natural and cereal coffee (Durand et al. 2012; Orecchio et al. 2009; Belitz et al. 2009; Tfouni et al. 2012). However, at the same time, roasting may lead to the formation of dangerous compounds such as furan, acrylamide and polycyclic aromatic hydrocarbons (PAHs; Tfouni et al. 2013). PAHs in coffee samples may also come from the contamination of green coffee beans (Houessou et al. 2008). The total concentration of PAHs detected in coffee was even as high as $1,589.70 \mu \mathrm{g} \mathrm{kg}^{-1}$ (Grover et al. 2013). Among PAHs, 15 of these compounds were recognised as mutagenic and carcinogenic by the Scientific Committee on Food (IARC 2014; Forsberg et al. 2011). Because of their planar hydrophobic chemical structure, PAHs are mainly distributed to lipophilic tissues, causing a variety of cancers in the lungs, stomach, pancreas, and breasts (Lee and Shin 2010; Ramalhosa et al. 2009; Rey-Salgueiro et al. 2009). Recently, based on the conclusions of European Food Safety Authority (EFSA), the European Commission 
established benzo $[a]$ pyrene, benzo $[a]$ anthracene, benzo $[b]$ fluoranthene and chrysene as suitable markers of PAH in food (EFSA 2008; Commission Regulation (EU) No 835/2011). According to this regulation, the sum of PAH markers in foods should not exceed $10 \mu \mathrm{g} \mathrm{kg}^{-1}$ for oils and fats, $35 \mu \mathrm{g} \mathrm{kg}^{-1}$ for cocoa beans and derived products, $30 \mu \mathrm{g} \mathrm{kg}^{-1}$ for smoked meat, meat products, fish, fishery products and sprats and $1 \mu \mathrm{g} \mathrm{kg}^{-1}$ for baby foods and dietary foods for special medical purposes. However, no European Union (EU) maximum levels have been established for coffee and coffee substitutes.

Numerous papers have been published on PAHs in coffee using different methods of analysis. In general, conventional methods of sample preparation include extraction with various solvents followed by a suitable cleanup. The final extract is usually analysed by gas or liquid chromatography coupled with one of variety detectors. The most popular extraction techniques are: Soxhlet extraction (Grover et al. 2013; Badolato et al. 2006) together with saponification (Lee and Shin 2010; Orecchio et al. 2009; Kukare et al. 2010), liquid-liquid extraction (LLE; Tfouni et al. 2012, 2013; García-Falcón et al. 2005; Bishnoi et al. 2005), accelerated solvent extraction (Rey-Salgueiro et al. 2009), and ultrasound-assisted extraction (Orecchio et al. 2009; Ramalhosa et al. 2009) using hexane, cyclohexane, dichloromethane, acetone, methanol, acetonitrile, ethyl acetate. Conventional cleanup strategies include solid-phase extraction (SPE) on cartridges with alumina, florisil, silica, C18, PS-DVB (Wieczorek et al. 2002; Tfouni et al. 2013; Lee and Shin 2010; Houessou et al. 2005; García-Falcón et al. 2005) or column chromatography with silica gel (Tfouni et al. 2012; Grover et al. 2013; Badolato et al. 2006). For the detection and quantification of PAHs in coffee, gas chromatography with flame ionisation detector (Grover et al. 2013), high performance liquid chromatography (HPLC) with photometric detection (Bishnoi et al. 2005), fluorimetric detection (Tfouni et al. 2012; Lee and Shin 2010; Houessou at el. 2005; García-Falcón et al. 2005; Ramalhosa et al. 2009) or mass spectrometry detection (ReySalgueiro et al. 2009) is often used. Another popular technique is gas chromatography coupled with mass spectrometry (Wieczorek et al. 2002; Orecchio et al. 2009; Kukare et al. 2010; Plaza-Bolanos et al. 2010).

Almost all of these sample preparation techniques are labour-intensive, time-consuming, require advanced analytical equipment and use large volumes of toxic and hazardous solvents. Moreover, many of these procedures do not perform well in more complex and difficult matrixes such as coffee. An alternative is the use of dispersive solid-phase extraction (dSPE), with use of different bulk sorbents, mainly primary secondary amine (PSA), but other sorbents, such as $\mathrm{C}_{18}$, strong anion exchange (SAX), $\mathrm{NH}_{2}$, graphitised carbon black (GCB) with different properties, are also used for better cleanup of the sample extract. For example, $\mathrm{NH}_{2}$ sorbent is a weak anion exchanger that removes strong acids, and SAX is a strong anion exchange sorbent used for the extraction of some carboxylic acids (Agilent Technologies 2013). The analytical procedure provides simple analytical operations, such as shaking and centrifugation, which significantly reduces the cost of analysis and time. Until now, dispersive SPE has been successfully and widely used to remove traces of the matrix in the determination of pesticide residues, mycotoxins and PAHs in various food samples, for example, in studies by Pizzutti et al. (2012), Forsberg et al. (2011), Dias et al. (2013) and Rodríguez-Carrasco et al. (2012). The application of liquidliquid extraction (LLE) at the end of the analytical procedure is another approach for cleanup of samples with a complex matrix. Obtained results confirmed the usefulness of this technique, resulting in a high percentage of removal of undesired matrix components. Co-extracts present in the crude organic extract were subsequently removed by liquid-liquid extraction using hexane with the assistance of added $20 \%$ (w/w) aqueous $\mathrm{NaCl}$ solution (Cajka et al. 2012).

The aim of the study was to evaluate the use of dispersive solid-phase extraction followed by LLE for PAH determination in samples of coffee, based on the modified QuEChERS method. In the first step, we optimised the analytical procedure using three types of sorbents (PSA, SAX and $\mathrm{NH}_{2}$ ), also testing the possibility of using LLE at the end of the analytical procedure. In the second step, an optimised procedure was subsequently applied in PAH determination in real samples of coffee.

\section{Materials and Methods}

\section{Chemicals and Reagents}

Hexane and acetonitrile, HPLC grade for liquid chromatography LiChrosolv ${ }^{\circledR}$ were purchased from Merck, Germany. Magnesium sulphate anhydrous p.a. and sodium chloride p.a., were purchased from Chempur, Poland. PSA, SAX and $\mathrm{NH}_{2}$ SPE bulk sorbent were derived from Agilent Technologies, USA. EPA 525 PAH Mix-B (containing: acenaphthylene, anthracene, benzo $[a]$ anthracene, benzo $[b]$ fluoranthene, benzo[ $k]$ fluoranthene, benzo $[a]$ pyrene, benzo $[g, h, i]$ perylene, chrysene, dibenzo $[a, h]$ anthracene, fluorene, indeno[1,2,3-cd]pyrene, phenanthrene, and pyrene), chrysene- $\mathrm{d}_{12}$ and anthracene- $\mathrm{d}_{10}$ were obtained from Supelco, USA. Stock, intermediate and working PAH standard solutions, chrysene- $\mathrm{d}_{12}$ (internal standard) and anthracene- $\mathrm{d}_{10}$ (syringe standard) at concentration $1 \mu \mathrm{g} \mathrm{ml}^{-1}$ were prepared in hexane. Deionised water $(18 \mathrm{M} \Omega)$ was produced by a Milli-Q system (Millipore, USA).

Instrumentation

The Varian $4000 \mathrm{GC} / \mathrm{MS}$ (Varian, USA) system consisting of a $3800 \mathrm{GC}$ with a CP-8410 auto-injector (Bruker, USA) and a 4000 Ion Trap MS detector was used to perform the GC-MS 
analyses. The injector was a CP-1177 split/splitless capillary injector, with a temperature of $270{ }^{\circ} \mathrm{C}$ and an injection volume of $1.0 \mu \mathrm{l}$. Each injection was performed in triplicate. Chromatographic separations were conducted using a DB$5 \mathrm{MS}$ column $(30 \mathrm{~m} \times 0.25 \mathrm{~mm} \times 0.25 \mu \mathrm{m}$; Agilent Technologies). The GC oven was operated with the following temperature program: initial temperature $50{ }^{\circ} \mathrm{C}(1.0 \mathrm{~min})-$ $15{ }^{\circ} \mathrm{C} \mathrm{min}{ }^{-1}-320{ }^{\circ} \mathrm{C}(6.0 \mathrm{~min})$. The total run time was $25 \mathrm{~min}$. Helium 5.0 (Linde Gas, Poland) was used as the GC carrier gas at a flow rate of $1.0 \mathrm{ml} \mathrm{min}^{-1}$. The ion trap mass spectrometre was operated in the internal ionisation mode, scan from $\mathrm{m} / \mathrm{z} 45$ to 500 . The emission current of the ionisation filament was set at $15 \mu \mathrm{A}$ and dwell time at $65 \mathrm{~ms}$. Analyses were conducted in the selected ion monitoring (SIM) mode based on the use of one quantitative ions. Analysed compounds were identified according to their qualitative ions and retention times (Table 1). The trap and the transfer line temperatures were set at 180 and $220^{\circ} \mathrm{C}$, respectively. The analyses were carried out with a solvent delay of $8.0 \mathrm{~min}$. Acquisition and processing data were performed using Varian Start Workstation software and NIST 2.0 library.

T25 digital ultra-turrax disperser (IKA, Germany), MS1 Minishaker (IKA), MPW 350 R Centrifuge (MPW Med. Instruments, Poland) were used during sample preparation. Accublock $^{\mathrm{TM}}$ (Labnet, USA) with nitrogen 5.0 (Linde Gas) was used to evaporate the solvent and to concentrate the extracts.

\section{Sample Preparation}

Coffee samples used for the preparation of blank and fortified samples were purchased from the local market. In the first step of the experiment, aside from PSA, we tested two additional sorbents $\left(\mathrm{NH}_{2}\right.$ and $\left.\mathrm{SAX}\right)$ and two procedures of final extract preparation (Fig. 1). In brief, the PAH extraction process from spiked coffee samples was conducted using hot water (improves extraction yield; Forsberg et al. 2011), acetonitrile followed by addition of $\mathrm{NaCl}$ and $\mathrm{MgSO}_{4}$. After hand shaking and centrifugation, the supernatant was cleaned up by an appropriate combination of sorbents (according to the scheme at Fig. 1) and $\mathrm{MgSO}_{4}$. The tubes were subsequently handshaken and centrifuged. Afterwards, the extract with addition of anthracene- $\mathrm{d}_{10}$ solution was: (1) evaporated under a stream of $\mathrm{N}_{2}$ to dryness (evaporation, E) or (2) hexane and $\mathrm{NaCl}$ aqueous solution were added, the mixture was shaken, and upper hexane layer was evaporated under a stream of $\mathrm{N}_{2}$ (liquid-liquid extraction, LLE). All residues were dissolved in hexane and then analysed by GC-MS. The final ratio of sample to extract was $0.4 \mathrm{~g} \mathrm{ml}^{-1}$ (E) or $0.35 \mathrm{~g} \mathrm{ml}^{-1}$ (LLE). Blank samples and reagent blanks were prepared similarly but were not fortified. Spiked reagent samples were also prepared to check for possible loss of analytes during the analytical procedure. Each sample was prepared in triplicate.
Standards Preparation

A series of standard solutions in hexane and in a matrix were prepared by dilution of the standard mixture solution at the following ranges: $0.1,1,5,10,40,70$ and $100 \mathrm{ng} \mathrm{ml}^{-1}$. Each standard solution contained $100 \mu$ of the anthracene- $\mathrm{d}_{10}$ solution and was prepared in triplicate. Calibration curves were constructed by plotting integrated peak areas, divided by the area of anthracene- $\mathrm{d}_{10}$, against concentrations of compounds. Peak areas have been reduced by the area of the peaks of compounds derived from blank matrix (or hexane). GC-MS chromatograms of standard solution in hexane, fortified sample and blank sample (both for the variant PSA + SAX + LLE) are presented in Fig. 2.

\section{Results and Discussion}

Optimisation of Sample Preparation Method

The use of additional sorbent in the sample preparation step, instead of only PSA, was considered to be necessary in order to better cleanup the sample extract. Thus, taking into account the coffee composition, especially the presence of phenolic acids, it was supposed that the use of $\mathrm{SAX}$ or $\mathrm{NH}_{2}$ enabled elimination of some interferents from coffee including phenolic compounds, according to their properties, as mentioned earlier. Finally, taking into consideration the results of other authors (Cajka et al. 2012), it was expected that liquid-liquid exchange at the end of the analytical process would give better results. The effectiveness of application of sorbents and LLE was verified based on recovery values. Also, a qualitative approach involving sample colour and the content of impurities and interferents present at the chromatograms was considered.

Recovery studies were conducted after fortification to the level of $20 \mu \mathrm{g} \mathrm{kg}^{-1}$. The best recoveries (within 50-120\%, according to Regulation 836/2011) for all compounds were provided by the combinations of SAX sorbent together with LLE (70-104 \%). The other variants resulted in much more diversified results of the recovery. The combination of sorbent SAX with evaporation (E) gave the values of the recovery in the range of $7-112 \%$, combination of sorbent $\mathrm{NH}_{2}$ with LLE yielded values of 50-123\%, and finally, the variant, $\mathrm{NH}_{2}+\mathrm{E}$, resulted in recovery values at ranges $35-141 \%$ (Fig. 3). In all cases, the highest recovery ratio was received for phenanthrene. The repeatability of recovery values for all tested variants, expressed as the relative standard deviation (RSD) of the spiked sample concentrations, was lower than $18 \%$ for all compounds. Nevertheless, comparing obtained results, it was shown that the technique of final extracts preparation (E or LLE) had a greater influence on recovery ratio that the type of sorbents used in the cleanup step. Except for the SAX+ 


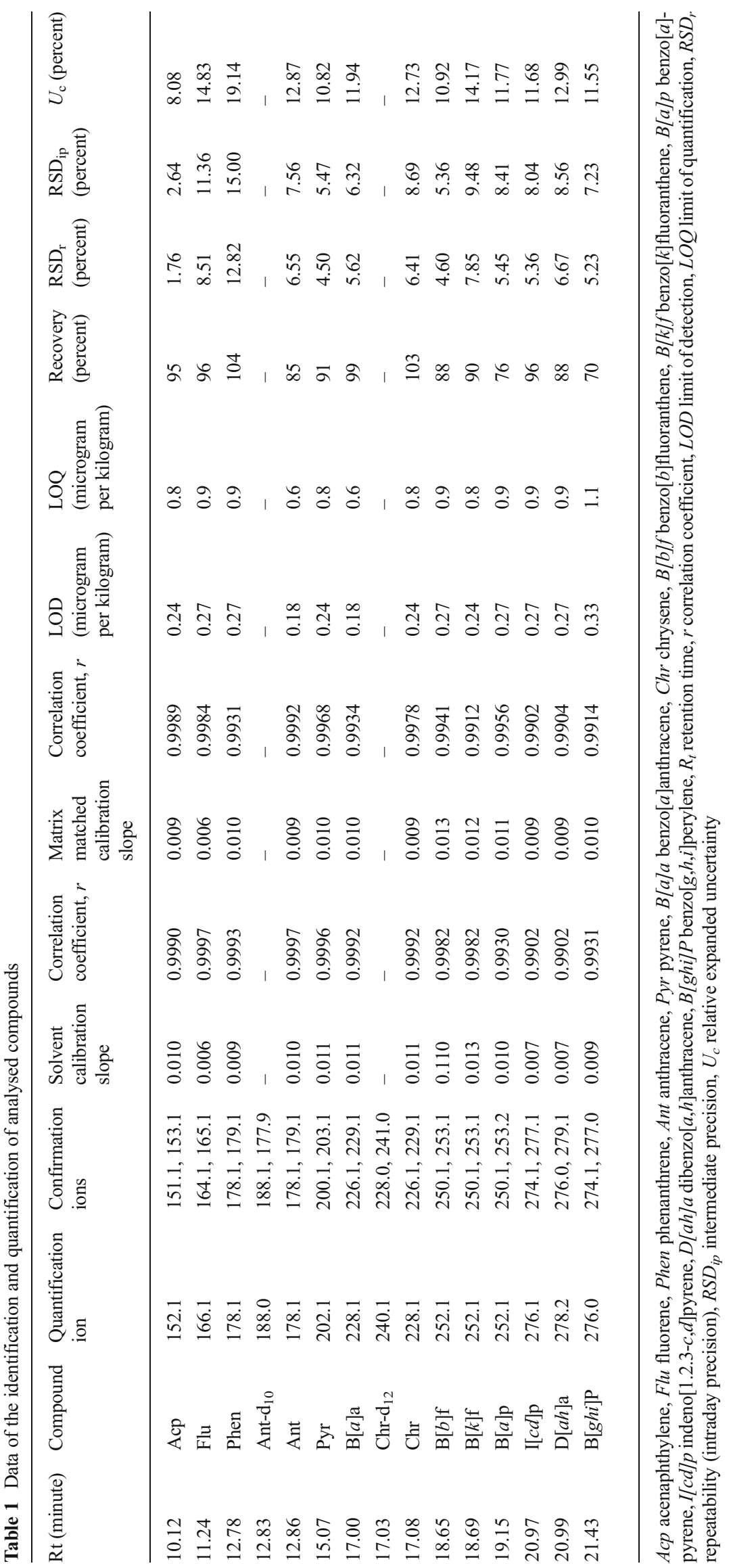




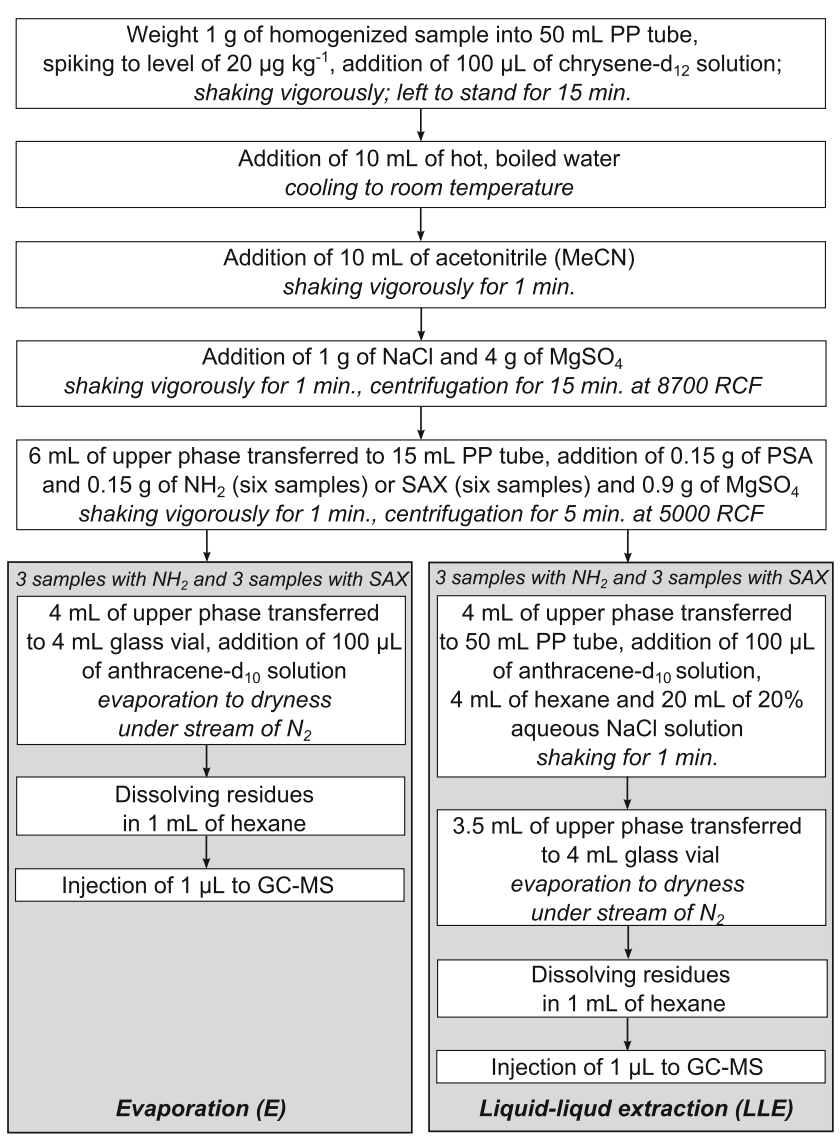

Fig. 1 Schema of the sample preparation procedure

LLE variant, the results achieved by the combination of $\mathrm{NH} 2+$ LLE were also satisfactory, slightly exceeding acceptable limits (phenanthrene, $123 \%$ ). Therefore, although LLE was an additional step of an analytical procedure during which analytes could be lost, the use of LLE resulted in better recovery results than simply using E. This phenomenon can be explained by the fact that during LLE, some interferents, which could interfere with analytes and disrupt GC-MS analysis, were removed from the samples of coffee (Fig. 4). There were no differences in extract colour after the use of SAX and $\mathrm{NH}_{2}$ and the chromatograms of spiked samples looked similar. On the other hand, in the case of samples where LLE was applied, a significant colour removal was observed, in contrast to samples after evaporation. Additionally, the occurrence of some interferents at the chromatograms of spiked samples after evaporation was noticed (Fig. 4). Hence, it can be concluded that the LLE technique used at the end of sample preparation can be successfully applied as an additional step of extract cleanup.

Once the selection of optimal variant was made, the appropriate quantity of sorbents was chosen. In the original procedure based on literature data (Kalachova et al. 2011), $0.15 \mathrm{~g}$ of PSA, a basic sorbent in dispersive SPE, is usually used. In this study, an additional $0.15 \mathrm{~g}$ of SAX was applied. Nonetheless, these two sorbents have similar properties and in some cases

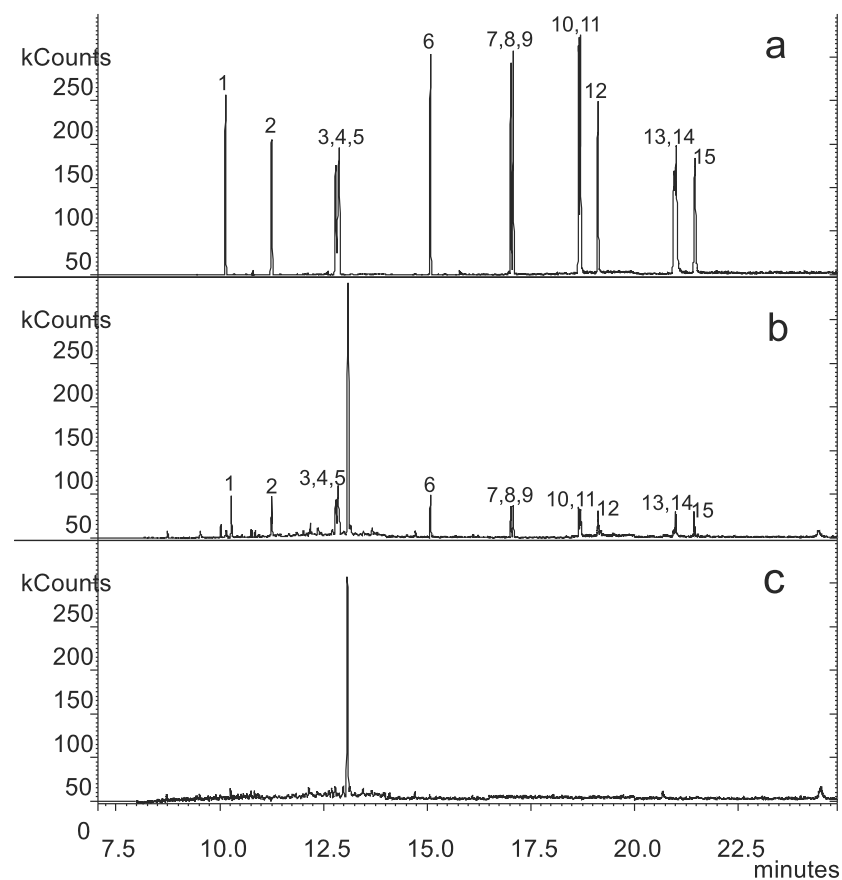

Fig. 2 GC-MS chromatograms of a standard mixture at concentration of $100 \mathrm{ng} \mathrm{ml}^{-1}$, b fortified sample (variant SAX+LLE), and $\mathbf{c}$ blank sample (variant SAX+LLE). 1 acenaphthylene, 2 fluorene, 3 phenanthrene, 4 anthracene- $\mathrm{d}_{10}, 5$ anthracene, 6 pyrene, 7 benzo $[a]$ anthracene, 8 chrysene- $\mathrm{d}_{12}, 9$ chrysene, 10 benzo[ $\left.b\right]$ fluoranthene, 11 benzo $[k]$ fluoranthene, 12 benzo[ $a]$ pyrene, 13 indeno[1,2,3-c,d]pyrene, 14 dibenzo[ $a, h]$ anthracene, 15 benzo $[g, h, i]$ perylene

can be used for removal of the same substances. Thus, optimisation of sorbent quantity and its proportion was another step of the experiment. Four combinations were tested: $0.15 \mathrm{~g}$ PSA $+0.15 \mathrm{~g}$ SAX, $0.15 \mathrm{~g}$ PSA $+0.3 \mathrm{~g} \mathrm{SAX}, 0.3 \mathrm{~g}$ PSA and $0.3 \mathrm{~g}$ SAX. Evaluation of the best combination was performed as previously described, based mainly on recovery values (Fig. 5), as the chromatograms and colour of the extracts were almost identical. The recovery values for three variants: $0.15 \mathrm{~g}$ PSA $+0.15 \mathrm{~g}$ SAX, $0.3 \mathrm{~g}$ PSA and $0.3 \mathrm{~g}$ SAX were within acceptable limits. The recovery was too low for phenanthrene ( $46 \%$ ), in the variant with the use of $0.15 \mathrm{~g} \mathrm{PSA}+0.3 \mathrm{~g} \mathrm{SAX}$. Based on these results, it was concluded that $0.3 \mathrm{~g}$ of sorbents was an optimal amount used for cleanup of $6 \mathrm{ml}$ of sample extract. Within these three combinations, the $0.15 \mathrm{~g}$ PSA+ $0.15 \mathrm{~g}$ SAX variant gave the most adequate results, approaching $100 \%$.

The last stage in the optimisation study involved verification of the addition of $\mathrm{NaCl}$ aqueous solution during LLE. The addition of this solution was used to enhance the transfer of compounds into the hexane layer by means of the salting out effect, as it was proposed by Cajka et al. (2012). However, some target analytes might not transfer into hexane layer, resulting in signal suppression. For this purpose, a comparison between LLE, LLE with addition of $\mathrm{NaCl}$ and also evaporation was performed. The experiment was conducted on a mixture of PAH standards, at concentrations of $0.1-$ 
Fig. 3 Recovery values for tested variants of the sample preparation method. $P S A, S A X, \mathrm{NH}_{2}$ sorbents, Eevaporation, $L L E$ liquid-liquid extraction, Acp acenaphthylene, Flu fluorene, Phen phenanthrene, Ant anthracene, Pyr pyrene, $B[a] a$ benzo $[a]$ anthracene, $C h r$ chrysene, $B[b] f$ benzo $[b]$ fluoranthene, $B[k] f$ benzo[k]fluoranthene, $B[a] p$ benzo $[a]$ pyrene, $I[c d] p$ indeno[1,2,3-c,d]pyrene, $D[a h] a$ dibenzo $[a, h]$ anthracene, $B[g h i] P$ benzo[ $[g, h, i]$ perylene

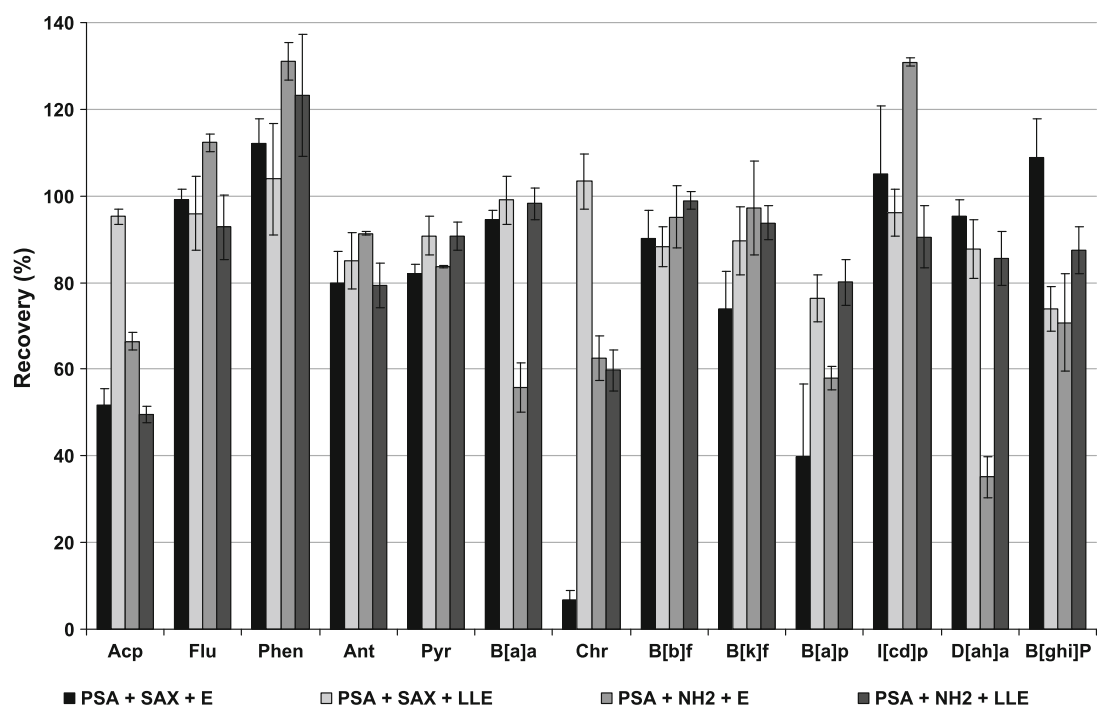

$100 \mathrm{ng} \mathrm{ml}^{-1}$. Four series of PAH standard solutions were prepared. The first series, prepared in hexane, remained without any operation as reference solutions. The second solution was evaporated to dryness and the residues were dissolved in hexane. The third solution was subjected to the LLE technique without $\mathrm{NaCl}$ addition, while the fourth solution was subjected to the LLE technique, but with addition of $\mathrm{NaCl}$ aqueous solution. After GC-MS analysis, four calibration curves were prepared for each compound. Additionally, a coverage factor $f$ was calculated for each compound, where $f$ was the ratio of the standard solution calibration slope to the standard calibration

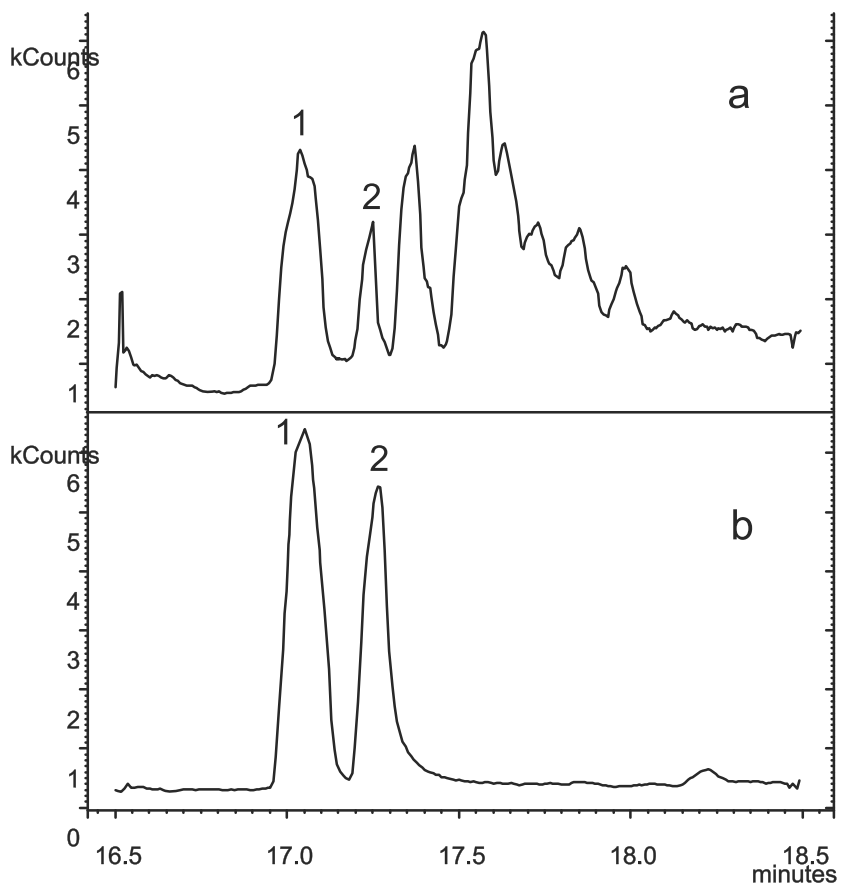

Fig. 4 GC-MS chromatograms of fortified samples: a preconcentrated with evaporation, and $\mathbf{b}$ treated with liquid-liquid extraction at the end of the analytical procedure. 1 benzo[a]anthracene, 2chrysene slope after E, LLE and LLE with addition of $\mathrm{NaCl}$. As shown in Fig. 6, the factor $f$ was nearly equal to $100 \%$ and was obtained in the case of LLE with the addition of $\mathrm{NaCl}$ solution. This demonstrates that the sensitivity of the calibration curves after LLE with $\mathrm{NaCl}$ was similar to those prepared directly in hexane. In the $\mathrm{LLE}+\mathrm{NaCl}_{\mathrm{aq}}$ solution, the addition of $\mathrm{NaCl}$ solution most likely pushed analytes from the acetonitrile layer to the hexane layer. In contrast, $f$ values calculated for $\mathrm{E}$ and $\mathrm{LLE}$ without addition of $\mathrm{NaCl}$ were much more varied, especially for pyrene and benzo $[b]$ fluorathene. Taken together, the data demonstrated the effectiveness and necessary addition of $\mathrm{NaCl}$ aqueous solution during LLE process.

\section{Validation Protocol}

The proposed analytical method was validated according to the criteria set by the EU (Regulation 836/2011) and also interpreting the general requirements for the competence of testing and calibration laboratories laid down in ISO standard 17025. The validation protocol included method specificity, linearity, limit of detection, limit of quantification, repeatability and intermediate precision, accuracy and uncertainty.

To characterise the specificity of the method, the possible presence of interfering compounds was investigated by analysing matrix matched samples The matrix showed no significant peaks interfering with the analytes across the range of retention times.

Linearity was evaluated by solvent and matrix-matched calibration, in which dilutions of the standard solution with the blank extract from the coffee matrix had been performed. The linearity, expressed as the correlation coefficient of the calibration slope from both solvent and matrix matched calibration, was higher than 0.99 for all compounds (Table 1). The matrix effect was also investigated by comparing the slopes in calibration solutions prepared in matrix and in a solvent. A 
Fig. 5 Recovery values for fours tested amounts of sorbents. Acp acenaphthylene, Flu fluorene, Phen phenanthrene, Ant anthracene, $P y r$ pyrene, $B[a] a$ benzo[ $a]$ anthracene, $C h r$ chrysene, $B[b] f$ benzo $[b]$ fluoranthene, $B[k] f$ benzo $[k]$ fluoranthene, $B[a] p$ benzo[ $a]$ pyrene, $I[c d] p$ indeno[1,2,3-c,d]pyrene, $D[a h] a$ dibenzo $[a, h]$ anthracene, $B[g h i] P$ benzo $[g, h, i]$ perylene

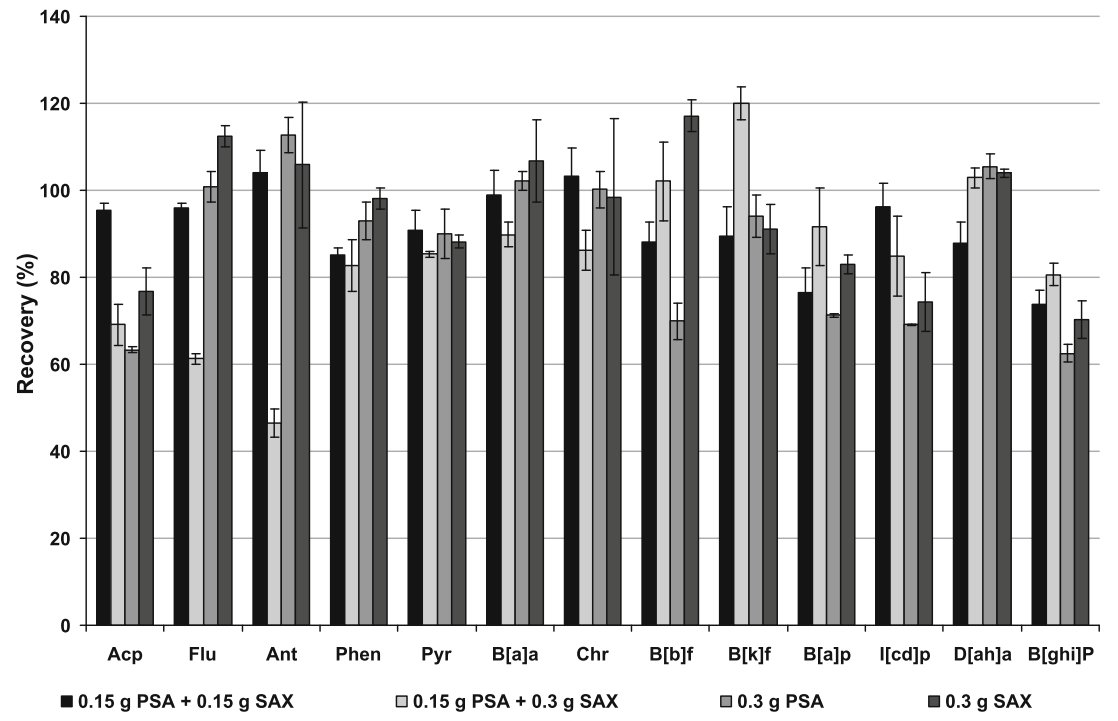

statistical comparison, evaluated by $t$ and $p$ values (Namieśnik et al. 2009), was performed between the calibration slopes obtained from solvent and matrix matched calibration in order to evaluate the matrix effect. For all compounds, except chrysene, no statistical differences were observed ( $p$ values for the comparison of the slopes were $>0.05$ ).

Limit of detection (LOD) and limit of quantification (LOQ) were calculated based on the signal of the background noise from the signal-to-noise ratio $(\mathrm{S} / \mathrm{N})$ measured by the MS software at the lowest calibration level. The limit of detection was calculated as three times higher than the level of noise, and the limit of quantification was equal to ten times the noise level. LOQs for all analysed PAHs were below $0.9 \mu \mathrm{g} \mathrm{kg}^{-1}$, except for benzo[g,h,i]perylene $\left(1.1 \mu \mathrm{g} \mathrm{kg}^{-1}\right)$.

The precision was evaluated in terms of repeatability (intraday precision) and intermediate precision (interday precision), both expressed as a relative standard deviation (RSD).
Repeatability was determined by analysing six spiking samples on the same day with the same instrument and the same operator, while the interday precision was calculated on the basis of the results from three different days and from the different operators. The obtained results were below 13 and $15 \%$, respectively.

Although no certified reference material of naturally contaminated coffee with PAHs was available, the accuracy of the method was determined with the percentage recovery using spiked coffee samples. The mean recovery for all PAHs was then calculated (Table 1). All results were within acceptable limits and ranged from 70 to $104 \%$.

Measurement uncertainty quantification was accomplished following the EURACHEM/CITAC guidelines (EURAC HEM 2012). Measurement uncertainty was calculated by identifying and quantifying the uncertainty components of whole analytical process for each PAH. The relative expanded
Fig. 6 Comparison of $f$ factor values for different methods of final precontcentration method, Acp acenaphthylene, Flu fluorene, Phen phenanthrene, Ant anthracene, $P y r$ pyrene, $B[a] a$ benzo[a]anthracene, $C h r$ chrysene, $B[b] f$ benzo[b]fluoranthene, $B[k] f$ benzo $[k]$ fluoranthene, $B[a] p$ benzo[ $[a]$ pyrene, $I[c d] p$ indeno[ $[1,2,3-c, d]$ pyrene, $D[a h] a$ dibenzo[ $a, h]$ anthracene, $B[g h i] P$ benzo $[g, h, i]$ perylene

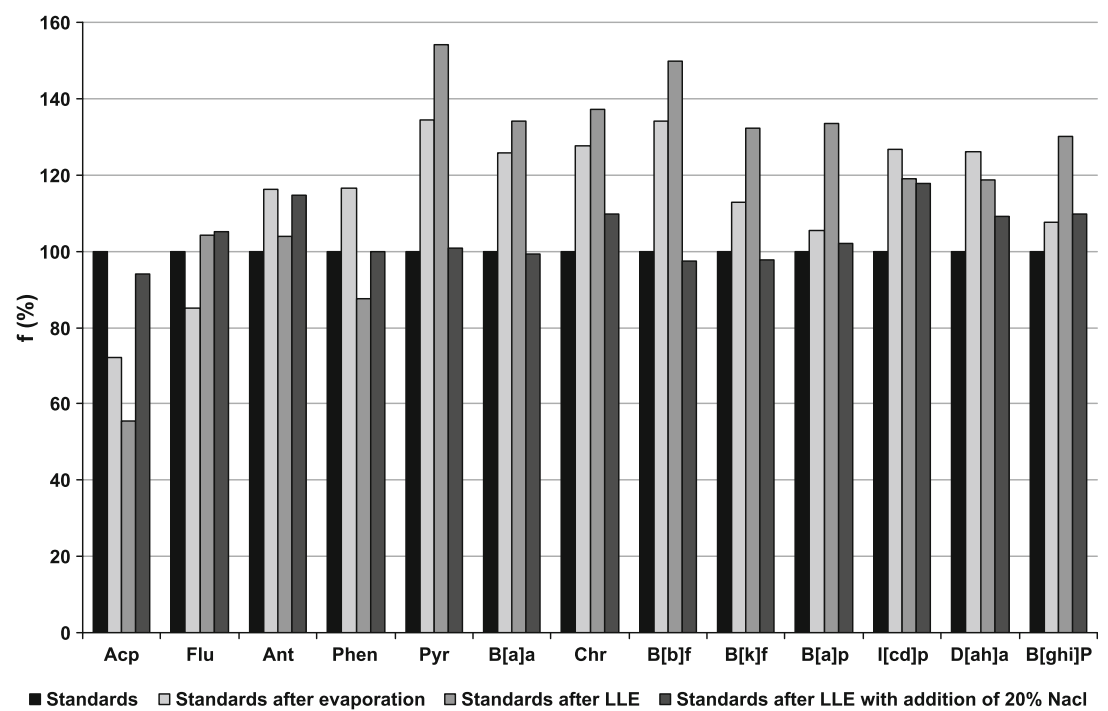




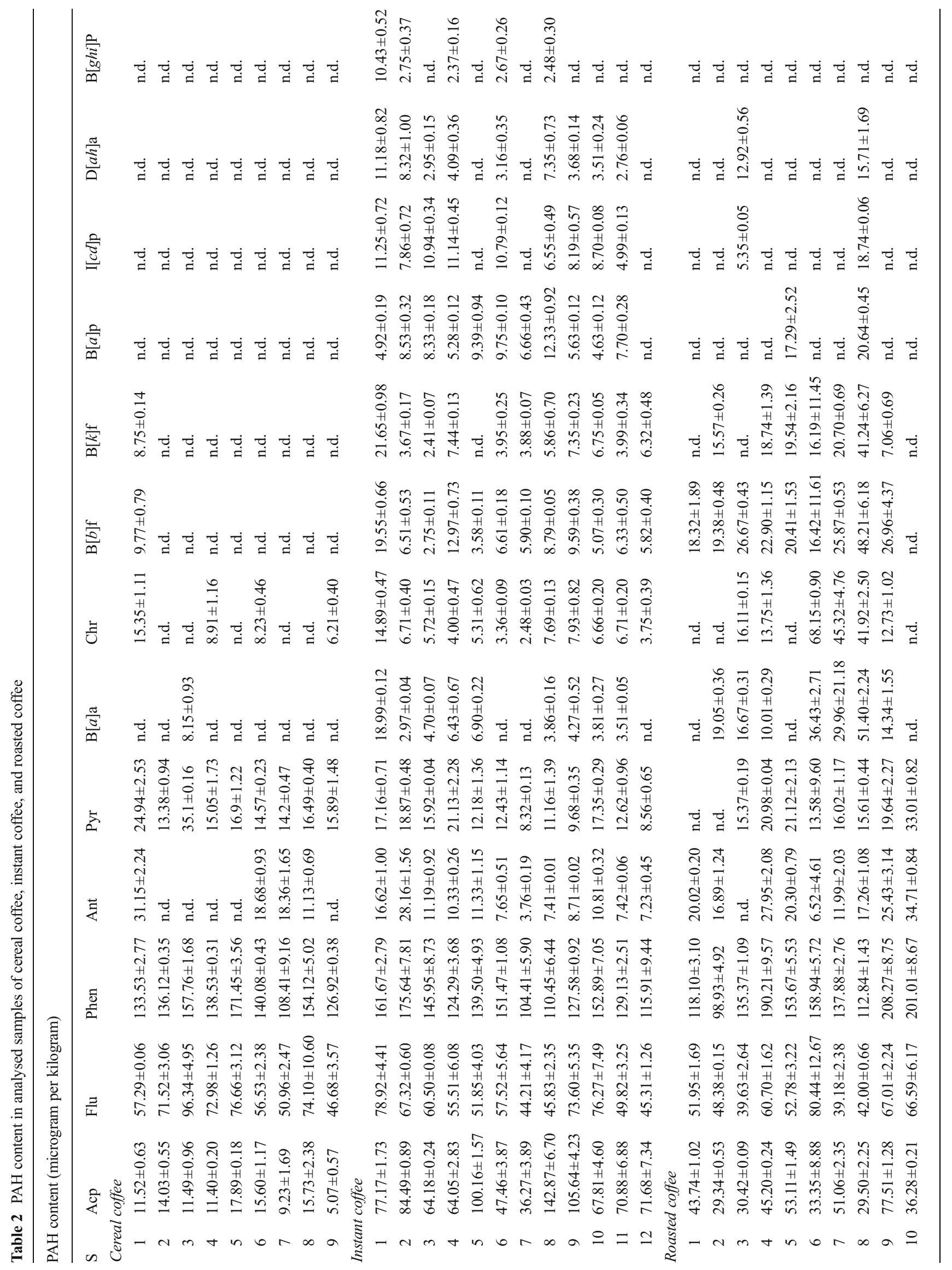


uncertainties $\left(U_{\mathrm{c}}\right)$, expressed as a percent value $(p=0.05 ; k=2)$ for all PAHs, were in the range 8.08-19.14 \% (Table 1).

Overall, the obtained results of the validation process met the established criteria in Commission Regulation (EU) No 836/2011 and were in a good agreement with previous work concerning PAHs analysis in coffee (Bishnoi et al. 2005; García-Falcón et al. 2005; Lee and Shin 2010).

\section{Real Sample Analysis}

In the final phase of the study, the optimised method was used to analyse 37 samples of various species of coffee including 16 samples of natural ground coffee, 12 samples of natural instant coffee and 9 samples of coffee substitutes. All samples were collected from the Polish market in 2013. Preparation of the samples was carried out according to the procedure described above with the application of PSA + SAX + LLE. The concentrations of PAHs detected in the coffee samples were displayed in Table 2. The PAH content depended mainly on the type of coffee. Nevertheless, within the same type of coffee the results were similar.

In all samples of coffee substitutes, three-ring PAHs prevailed in the total sum of PAHs (90\%). Acenaphthylene, fluorene, phenanthrene and pyrene were the most abundant compounds, and phenanthrene was detected at the highest level (108.41-171.45 $\mathrm{g} \mathrm{kg}^{-1}$ ). PAH markers were detected rarely in the analysed samples, benzo[b]fluoranthene and benzo $[a]$ pyrene in one sample and chrysene in three samples. In the case of instant coffee, the PAH distribution in all samples was slightly different. The target compounds were identified in almost all analysed samples with the exception of benzo $[g, h, i]$ perylene, which was found only in five samples at the lowest concentration level. Three-ring PAHs dominated within the identified compounds $(88 \%)$ and phenanthrene was also the most abundant compound (104.41$\left.175.64 \mu \mathrm{g} \mathrm{kg}^{-1}\right)$. The concentrations of four PAH markers were in the range of $2.48-19.55 \mu \mathrm{g} \mathrm{kg}^{-1}$.

In the samples of roasted coffee, acenaphthylene, fluorene, phenanthrene, anthracene and pyrene were detected in almost all samples. Similarly to coffee substitutes and instant coffee, three-ring PAHs dominated within the identified compounds (77\%), and phenanthrene was the compound detected at the highest concentration (95.39-209.67 $\mu \mathrm{g} \mathrm{kg}^{-1}$ ). PAH markers were found in analysed samples in the range of 7.2 $68.15 \mu \mathrm{g} \mathrm{kg}^{-1}$. Within these compounds, benzo[a]anthracene was found in 11 samples, chrysene in 6 samples, benzo[b]fluorathene in 9 samples, and benzo $[a]$ pyrene in only 3 samples of coffee.

Comparing the obtained results for all types of coffee, the levels of analysed compounds were lowest for the samples of coffee substitutes, while the samples of natural roasted coffee contained much more PAHs. Statistical significance of these results was confirmed by $t$ test with a $p$ value of 0.05 . For 
Table 3 Comparison of PAH contents in coffee determined by different authors

\begin{tabular}{|c|c|c|c|c|c|c|}
\hline Sampling place & Coffee type & $\mathrm{B}[\mathrm{a}] \mathrm{a}$ & $\mathrm{Chr}$ & $\mathrm{B}[b] \mathrm{f}$ & $\mathrm{B}[a] \mathrm{p}$ & $\Sigma \mathrm{PAH}$ \\
\hline \multicolumn{7}{|l|}{ PAH content (microgram per kilogram) } \\
\hline Poland (this study) & Coffee substitute & 8.15 & $6.21-15.35$ & 9.77 & n.d. & $200.70-308.80$ \\
\hline Poland (this study) & Natural instant coffee & $2.97-18.99$ & $2.48-14.89$ & $2.75-19.55$ & $4.63-12.33$ & $215.90-464.40$ \\
\hline Poland (this study) & Natural roasted coffee & $7.20-51.40$ & $12.73-68.15$ & $16.42-48.21$ & $17.29-34.84$ & $224.70-459.00$ \\
\hline Brasil (Badolato et al. 2006) & Natural roasted coffee & n.a. & n.a. & n.a. & $0.47-12.52$ & n.a. \\
\hline Romania (Stanciu et al. 2008) & Natural instant coffee & 0.47 & n.a. & 0.11 & 0.86 & n.a. \\
\hline Romania (Stanciu et al. 2008) & Natural roasted coffee & 0.74 & n.a. & 0.22 & 0.29 & n.a. \\
\hline Spain (Ballesteros-Gomez et al. 2009) & Natural instant coffee & n.a. & n.a. & n.a. & 220.00 & n.a. \\
\hline Korea (Lee and Shin 2010) & n.a. & $0.15-1.57$ & $0.17-1.90$ & $0.85-3.90$ & $0.09-0.36$ & $0.62-53.25$ \\
\hline India (Grover et al. 2013) & Natural instant coffee & $92.80-106.60$ & 95.00 & 17.70 & 98.30 & $831.70-1589.70$ \\
\hline \multicolumn{7}{|l|}{ PAH content (microgram per liter) } \\
\hline Poland (this study) & Coffee substitute & 0.24 & $0.19-0.46$ & 0.29 & n.d. & $6.02-9.26$ \\
\hline Poland (this study) & Natural instant coffee & $0.04-0.24$ & $0.03-0.19$ & $0.03-0.24$ & $0.06-0.15$ & $2.70-5.81$ \\
\hline Poland (this study) & Natural roasted coffee & $0.16-1.16$ & $0.29-1.53$ & $0.37-1.08$ & $0.39-0.78$ & $5.06-10.33$ \\
\hline Spain (Kayali-Sayadi et al. 1999) & Natural roasted coffee & $0.001-0.003$ & $0.001-0.002$ & n.a. & $0.002-0.003$ & n.a. \\
\hline Poland (Wieczorek et al. 2002) & Natural roasted coffee & $0.01-0.07$ & 0.03 & $0.03-0.05$ & n.d. & n.a. \\
\hline Poland (Wieczorek et al. 2002) & Coffee substitute & $0.01-0.06$ & n.d. & n.d. & n.d. & n.a. \\
\hline India (Bishnoi et al. 2005) & n.a. & $0.06-0.10$ & n.a. & n.d. & $0.25-0.46$ & $16.47-18.24$ \\
\hline Spain (Ballesteros-Gomez et al. 2009) & Natural instant coffee & n.a. & n.a. & n.a. & 0.001 & n.a. \\
\hline Italy (Orecchio et al. 2009) & Natural roasted coffee & $0.001-0.16$ & $0.002-0.14$ & $0.001-0.04$ & $0.001-0.05$ & $0.76-1.80$ \\
\hline India (Grover 2013) & Natural instant coffee & $4.60-5.30$ & 4.70 & 0.90 & 4.90 & n.a. \\
\hline
\end{tabular}

$B[a] a$ benzo $[a]$ anthracene, $C h r$ chrysene, $B[b] f$ benzo $[b]$ fluoranthene, $B[a] p$ benzo $[a]$ pyrene, $n . a$. data not available in the study, $n . d$. not detected

Table 4 Phe/Ant, Ant/Phe + Ant and B $[a] \mathrm{a} / \mathrm{B}[a] \mathrm{a}+\mathrm{Chr}$ ratio calculated for analysed samples of coffee

\begin{tabular}{|c|c|c|c|c|c|c|c|c|c|c|c|}
\hline \multirow[t]{2}{*}{ Sample \# } & Phe/Ant & Ant/Phe+Ant & $\begin{array}{l}\mathrm{B}[a] \mathrm{a} / \mathrm{B}[a] \\
\mathrm{a}+\mathrm{Chr}\end{array}$ & Sample \# & Phe/Ant & $\mathrm{Ant} / \mathrm{Phe}+\mathrm{Ant}$ & $\begin{array}{l}\mathrm{B}[a] \mathrm{a} / \mathrm{B}[a] \\
\mathrm{a}+\mathrm{Chr}\end{array}$ & Sample \# & Phe/Ant & Ant/Phe+Ant & $\begin{array}{l}\mathrm{B}[a] \mathrm{a} / \mathrm{B}[a] \\
\mathrm{a}+\mathrm{Chr}\end{array}$ \\
\hline & \multicolumn{4}{|c|}{ Cereal coffee } & \multicolumn{4}{|c|}{ Instant coffee } & \multicolumn{3}{|c|}{ Roasted coffee } \\
\hline 1 & 4.29 & 0.19 & 0.00 & 1 & 9.73 & 0.09 & 0.56 & 1 & 5.90 & 0.14 & n.c. \\
\hline 2 & n.c. & 0.00 & n.c. & 2 & 6.24 & 0.14 & 0.31 & 2 & 5.86 & 0.15 & 1.00 \\
\hline 3 & n.c. & 0.00 & 1.00 & 3 & 13.04 & 0.07 & 0.45 & 3 & n.c. & 0.00 & 0.51 \\
\hline 4 & n.c. & 0.00 & 0.00 & 4 & 12.03 & 0.08 & 0.62 & 4 & 6.80 & 0.13 & 0.42 \\
\hline 5 & n.c. & 0.00 & n.c. & 5 & 12.31 & 0.08 & 0.57 & 5 & 7.56 & 0.12 & n.c. \\
\hline 6 & 7.50 & 0.12 & 0.00 & 6 & 19.79 & 0.05 & 0.00 & 6 & 24.37 & 0.04 & 0.35 \\
\hline 7 & 5.90 & 0.14 & n.c. & 7 & 27.79 & 0.03 & 0.00 & 7 & 11.50 & 0.08 & 0.40 \\
\hline 8 & 13.85 & 0.07 & n.c. & 8 & 14.90 & 0.06 & 0.33 & 8 & 6.54 & 0.13 & 0.55 \\
\hline \multirow[t]{8}{*}{9} & n.c. & 0.00 & 0.00 & 9 & 14.64 & 0.06 & 0.35 & 9 & 8.19 & 0.11 & 0.53 \\
\hline & & & & 10 & 14.14 & 0.07 & 0.36 & 10 & 5.79 & 0.15 & n.c. \\
\hline & & & & 11 & 17.41 & 0.05 & 0.34 & 11 & n.c. & 0.00 & 1.00 \\
\hline & & & & 12 & 16.03 & 0.06 & 0.00 & 12 & 9.11 & 0.10 & n.c. \\
\hline & & & & & & & & 13 & n.c. & 0.00 & n.c. \\
\hline & & & & & & & & 14 & 4.67 & 0.18 & 1.00 \\
\hline & & & & & & & & 15 & 9.37 & 0.10 & 0.64 \\
\hline & & & & & & & & 16 & n.c. & 0.00 & 0.30 \\
\hline
\end{tabular}

Bolded values indicated combustion process as a source of PAHs

$S$ sample, Phe phenanthrene, Ant anthracene, $B[a] a$ benzo $[a]$ anthracene, $C h r$ chrysene 
acenaphthylene, benzo $[a]$ anthracene, benzo $[b]$ fluoranthene, benzo $[k]$ fluoranthene and indeno $[c, d]$ pyrene significant statistical differences between different coffee types were shown.

The average total sum of PAHs for coffee substitutes, instant coffee and roasted coffee was 265, 343 and $364 \mu \mathrm{g} \mathrm{kg}^{-1}$, respectively. The concentration of heavy, fivering PAHs was the highest in roasted coffee. These results probably arise from the manufacturing process of instant coffee. Instant coffee is obtained by the extraction of roasted coffee with hot water to recover the coffee flavour and aroma. During this process, light PAHs, which are more soluble in water, mainly pass into a coffee brew. Therefore, instant coffee samples might contain more light hydrocarbons than roasted coffee.

As mentioned before, no EU maximum levels have been established for coffee and coffee substitutes. In spite of this fact, the monitoring of PAHs in foods is extremely important and essential for public health. Hence, several papers have been published on the subject of PAH levels in coffee. In the study by Grover et al. (2013), 13 PAHs were detected in four brands of ground coffee. Concentrations of total PAHs were in the range of $831.7-1,589.7 \mu \mathrm{g} \mathrm{kg}^{-1}$. In another study, the concentrations of PAHs in ten coffee samples ranged from 0.62 to $53.25 \mu \mathrm{g} \mathrm{kg}^{-1}$ (Lee and Shin 2010). In a study by Orecchio et al. (2009), the sum of total PAHs in coffee brew varied from 0.52 to $1.8 \mu \mathrm{g} \mathrm{l}^{-1}$, and carcinogenic PAHs, expressed as a benzo $[a]$ pyrene equivalent, ranged from 0.008 to $0.060 \mu \mathrm{g} \mathrm{l}^{-1}$. Results of a study conducted in India (Bishnoi et al. 2005) showed that the concentration of total PAHs in different brands of coffee samples varied from 16.47 to $18.24 \mu \mathrm{g} \mathrm{l}^{-1}$. In research by Stanciu et al. (2008), it was found that concentrations of PAHs in coffee samples varied from 0.001 to $90.732 \mu \mathrm{g} \mathrm{kg}^{-1}$. Finally, in a study by another Polish group, the highest concentration of investigated PAHs in coffee samples was found in natural roasted coffee $\left(0.12 \mu \mathrm{g} \mathrm{l}^{-1}\right)$ and was higher than the content in cereal coffee (Wieczorek et al. 2002). The comparison of the levels of selected compounds belonging to PAH markers and the sums of total PAHs provided by us and other researchers are presented in Table 3. However, since some authors expressed their results in $\mu \mathrm{gl}^{-1}$, the data achieved in this study $\left(\mu \mathrm{g} \mathrm{kg}^{-1}\right)$ were recalculated into $\mu \mathrm{g}^{-1}$, assuming that coffee brew would be prepared in accordance with the brewing instructions presented on the coffee package. In this case, the results obtained in our study were comparable only with the results reported by Bishnoi et al. (2005) and were relatively higher than those presented by other authors, except for Grover et al. (2013). In terms of coffee substitute, according to available literature, its samples were examined only once in Poland, by Wieczorek et al. (2002). The authors reported the presence of benzo $[a]$ anthracene in examined samples, at a level of $0.01-$ $0.06 \mu \mathrm{g} \mathrm{l}^{-1}$, which was lower than the result obtained in this study.
Finally, some authors report that the high-temperature processes (combustion) generate PAHs characterised by a low phenanthrene/anthracene $(<10)$ ratio, whereas the slow maturation of organic matter during catagenesis leads to much higher values (Baumard et al. 1998). Another factor is the ratio of anthracene to anthracene plus phenanthrene Ant/(Ant + Phen), which has a value $<0.10$ and is usually an indication of low temperature sources (petroleum), while a ratio $>0.10$ indicates a dominance of combustion. The third indicator is $\mathrm{B}[a] \mathrm{a} /(\mathrm{B}[a] \mathrm{a}+\mathrm{Chr})$ ratios. Values $<0.20$ involve petroleum, values from 0.20 to 0.35 indicate either petroleum or combustion and $>0.35$ imply combustion sources. Lastly, the light (three-ring) PAHs/heavy (four and five-ring) PAHs ratio indicates that the lower the values, the higher the prevalence of pyrolytic on petrogenic origin of PAHs (Orecchio et al. 2009). For analysed samples of coffee substitutes and instant coffee, the values of these factors indicated that PAHs originated from other sources rather than combustion processes (Table 4), whereas in the case of roasted coffee, hydrocarbons were probably derived from pyrolytic processes. However, taking into account the light PAHs/ heavy PAHs ratios, this suggests a petrogenic origin of PAHs. This fact can be explained by the sample preparation process, during which hot water was used to improve PAH extraction from samples. This likely led to improve the transfer of light PAHs to extracts, increasing its concentration, in contrast to heavy PAHs.

\section{Conclusions}

The results indicated that cleanup with PSA and SAX sorbents followed by final solvent exchange from acetonitrile to hexane (LLE) with the addition of $\mathrm{NaCl}$ aqueous solution was the best variant of the method. This resulted in the cleanest extracts and satisfactory compound recoveries for examined samples of coffee. In the study of real samples, natural coffee was significantly more contaminated with PAH markers than instant and cereal coffee. The sum of analysed compounds was higher in natural coffee in comparison to coffee made from cereals. In all samples of coffee, three-ring PAHs dominated within identified compounds and phenanthrene was the most abundant compound.

The obtained results, especially the occurrence of PAH markers in the examined samples, indicate the need to monitor the presence of PAHs in coffee. Establishing MRLs for PAHs in coffee is also necessary to estimate the human exposure to the effects of these compounds.

Acknowledgements This research was performed with the financial support of the University of Agriculture in Cracow for young scientists and doctoral students (grant for Dr. Anna Sadowska-Rociek, no. BM4745/KTGiK/2013), which is hereby gratefully acknowledged. 
Conflict of Interest Anna Sadowska-Rociek declares that she has no conflict of interest. Magdalena Surma declares that she has no conflict of interest. Ewa Cieślik declares that she has no conflict of interest. Anna Sadowska-Rociek declares that she has not received any research grants and any honoraries from any commercial companies. Magdalena Surma declares that she has not received any research grants and any honoraries from any commercial companies. Ewa Cieślik declares that she has not received any research grants and any honoraries from any commercial companies. This article does not contain any studies with human or animal subjects.

Open Access This article is distributed under the terms of the Creative Commons Attribution License which permits any use, distribution, and reproduction in any medium, provided the original author(s) and the source are credited.

\section{References}

Agilent Technologies (2013) Agilent products for solid phase extraction brochure. Agilent Technologies. http://www.chem.agilent.com. Accessed 23 May 2013

Badolato ESG, Martins MS, Aued-Pimentel S, Alaburda J, Kumagai EE, Baptista GG, Rosenthal A (2006) Sistematic study of benzo[a]pyrene in coffee samples. J Braz Chem Soc 17:989-993

Ballesteros-Gomez A, Rubio S, Perez-Bendito D (2009) Potential of supramolecular solvents for the extraction of contaminants in liquid foods. J Chromatogr A 1216:530-539

Baumard P, Budzinski H, Garrigues P (1998) Polycyclic aromatic hydrocarbons in sediments and mussels of the Western Mediterranean Sea. Environ Toxicol Chem 17:765-776

Belitz HD, Grosch W, Schieberle P (2009) Coffee, tea, cocoa. In: Chemistry F (ed) 4th rev, extth edn. Springer, Berlin, pp 938-970

Bishnoi NR, Mehta U, Sain U, Pandit GG (2005) Quantification of polycyclic aromatic hydrocarbons in tea and coffee samples of Mumbai City (India) by high performance liquid chromatography. Environ Monit Assess 107:399-406

Cajka T, Sandy C, Bachanova V, Drabova L, Kalachova K, Pulkrabova J, Hajslova J (2012) Streamlining sample preparation and gas chromatography-tandem mass spectrometry analysis of multiple pesticide residues in tea. Anal Chim Acta 743:51-60

Cano-Marquina A, Tarín JJ, Cano A (2013) The impact of coffee on health. Maturitas 75(1):7-21

Commission Regulation (EU) No 835/2011 of 19 August 2011 amending regulation (EC) no 1881/2006 as regards maximum levels for polycyclic aromatic hydrocarbons in foodstuffs

Commission Regulation (EU) No 836/2011 of 19 August 2011 amending regulation (EC) no 333/2007 laying down the methods of sampling and analysis for the official control of the levels of lead, cadmium, mercury, inorganic tin, 3-MCPD and benzo $(a)$ pyrene in foodstuffs

Dias CM, Oliveira FA, Madureira FD, Silva G, Souza WR, Cardeal ZL (2013) Multi-residue method for the analysis of pesticides in Arabica coffee using liquid chromatography/tandem mass spectrometry. Food Addit Contam A 30(7):1308-1315

Durand N, Gueule D, Fourny G (2012) Les contaminants du café. Cah Agric 21:192-196

EFSA, European Food Safety Authority (2008) Findings of the EFSA data collection on polycyclic aromatic hydrocarbons in food. A report from the unit of data collection and exposure on a request from the European Commission. EFSA. http://www.efsa.europa.eu/ en/efsajournal/doc/33r.pdf. Accessed 11 Dec 2013

EURACHEM/CITAC Guide CG 4. (2012) Quantifying uncertainty in analytical measurement, $3 \mathrm{rd}$ edn
Forsberg ND, Wilson GR, Anderson KA (2011) Determination of parent and substituted polycyclic aromatic hydrocarbons in high-fat salmon using a modified QuEChERS extraction, dispersive SPE and GCMS. J Agric Food Chem 59:8108-8116

García-Falcón MS, Cancho-Grande B, Simal-Gandara J (2005) Minimal clean-up and rapid determination of polycyclic aromatic hydrocarbons in instant coffee. Food Chem 90:643-647

Grover IS, Sharma R, Singh S, Pal B (2013) Polycyclic aromatic hydrocarbons in some grounded coffee brands. Environ Monit Assess 185:6459-6463

Houessou JK, Benac C, Delteil C, Camel RV (2005) Determination of polycyclic aromatic hydrocarbons in coffee brews using solid-phase extraction. J Agric Food Chem 53:871-879

Houessou JK, Goujot D, Heyd B, Camel RV (2008) Modelling the formation of some polycyclic aromatic hydrocarbons during the roasting of arabica coffee samples. J Agric Food Chem 56:3648-3656

IARC, International Agency for Research on Cancer (2014) IARC monographs on the evaluation of carcinogenic risks to humans: Volume 92. Some non-heterocyclic polycyclic aromatic hydrocarbons and some related exposures. IARC. http://www.iarc.fr. Accessed 20 February 2014

Kalachová K, Pulkrabová J, Drábová L, Čajka T, Kocourek V, Hajšlová J (2011) Simplified and rapid determination of polychlorinated biphenyls, polybrominated diphenyl ethers, and polycyclic aromatic hydrocarbons in fish and shrimps integrated into a single method. Anal Chim Acta 707:84-91

Kayali-Sayadi MN, Rubio-Barroso S, Cuesta-Jimenez MP, Polo-Díez LM (1999) A new method for the determination of selected PAHs in coffee brew samples by HPLC with fluorimetric detection and solid-phase extraction. J Liq Chrom \& Rel Technol 22:615-627

Kukare A, Bartkevics V, Viksna A (2010) Development of methodology for control of polycyclic aromatic hydrocarbon content in food. Latvian Journal of Chemistry 1-4:54-65

Lee K, Shin H-S (2010) Determination of polycyclic aromatic hydrocarbons in commercial roasted coffee beans. Food Technol Biotech 19: $1435-1440$

Namieśnik J, Konieczka P, Zygmunt B (2009) Quality control of analytical measurements results, 1 st edn. WNT, Warsaw

Orecchio S, Paradiso Ciotti V, Culotta L (2009) Polycyclic aromatic hydrocarbons (PAHs) in coffee brew samples: analytical method by GC-MS, profile, levels and sources. Food Chem Toxicol 47:819-826

Pizzutti IR, de Kok A, Dickow Cardoso C, Reichert B, de Kroon M, Wind W, Weber Righi L, Caiel da Silva R (2012) A multi-residue method for pesticides analysis in green coffee beans using gas chromatography-negative chemical ionization mass spectrometry in selective ion monitoring mode. J Chromatogr A 1251:16-26

Plaza-Bolanos P, Garrido Frenich A, Martínez Vidal JL (2010) Polycyclic aromatic hydrocarbons in food and beverages. Analytical methods and trends. J Chromatogr A 1217:6303-6326

Ramalhosa MJ, Paiga P, Morais S, Delerue-Matos C, Prior Pinto Oliveira MB (2009) Analysis of polycyclic aromatic hydrocarbons in fish: evaluation of a quick, easy, cheap, effective, rugged, and safe extraction method. J Sep Sci 32:3529-3538

Rey-Salgueiro L, Martínez-Carballo E, García-Falcón MS, GonzálezBarreiro C, Simal-Gándara J (2009) Occurrence of polycyclic aromatic hydrocarbons and their hydroxylated metabolites in infant foods. Food Chem 115:814-819

Rodríguez-Carrasco Y, Berrada H, Font G, Manes J (2012) Multimycotoxin analysis in wheat semolina using an acetonitrile-based extraction procedure and gas chromatography-tandem mass spectrometry. J Chromatogr A 1270:28-40

Stanciu G, Dobrinas S, Birghila S, Popescu M (2008) Determination of organic compounds from different types of coffee by HPLC and GC-ECD analysis. Environ Eng Manage J 7:661-666

Tfouni SAV, Serrate CS, Carreiro LB, Camargo MCR, Teles CRA, Cipolli KMVAB, Furlani RPZ (2012) Effect of roasting on 
chlorogenic acids, caffeine and polycyclic aromatic hydrocarbons levels in two Coffea cultivars: Coffea arabica cv. Catual' Amarelo IAC-62 and Coffea canephora cv. Apoata IAC-2258. Int J Food Sci Tech 47:406-415

Tfouni SAV, Serrate CS, Leme FM, Camargo MCR, Teles CRA, Cipolli KMVAB, Furlani RPZ (2013) Polycyclic aromatic hydrocarbons in coffee brew: influence of roasting and brewing procedures in two Coffea cultivars. Food Sci Technol-Leb 50:526-530

Wieczorek J, Mozolewski W, Smoczyńska K, Wieczorek Z (2002) The occurrence of polycyclic aromatic hydrocarbons (PAHs) in infusion of natural coffee, coffee substitute and cocoa. Ann National Institute of Hygiene 53:231-236 (in Polish) 